\title{
Home literacy e alfabetização: uma revisão sistemática da literatura
}

\author{
Home literacy and literacy: a systematic literature review
}

\footnotetext{
Doutora em Psicologia, professora do Programa de Pós-Graduação em Psicologia da Universidade Salgado de Oliveira (Universo) e do Programa de Pós-Graduação em Psicologia Social da Universidade do Estado do Rio de Janeiro (UERJ), Rio de Janeiro, RJ - Brasil, e-mail: mmotapsi@ gmail.com
}

Recebido: $17 / 03 / 2012$ Received: 03/17/2012

Aprovado: 18/11/2012 Approved: $11 / 18 / 2012$
Márcia Maria Peruzzi Elia da Mota

\section{Resumo}

O conceito de home literacy pode ser definido como as experiências com língua escrita no contexto da família. Essas experiências estão associadas ao desempenho da leitura e escrita e ao sucesso na escolarização em geral. Embora a literatura internacional aponte vários estudos que mostram a importância desse constructo para o sucesso acadêmico, no Brasil não encontramos estudos empíricos sobre o tema. 0 presente trabalho apresenta uma revisão da literatura na área que discute a necessidade de se conceituar adequadamente home literacy, apresenta dados empíricos que corroboram sua importância para alfabetização e aponta diferenças culturais nas práticas de leitura. 0 presente trabalho sugere também caminhos para pesquisas futuras no contexto nacional.

Palavras-chave: Alfabetização. Letramento. Desempenho escolar. Home literacy. Nível socioeconômico e alfabetização.

\begin{abstract}
The concept of home literacy can be defined as the home experiences with written language within the family context. These experiences are associated with the performance of reading and writing and success in schooling in general. Although the international literature reports many studies that show the importance of this construct for academic success, in Brazil we did not find empirical studies on this subject. This study presents a literature review in the field that discusses the importance of adequately conceptualize home literacy, presents empirical data supporting its importance and points to cultural differences in reading practices. The present study also suggests ways for future research in the national context.
\end{abstract}

Keywords: Literacy. Academic performance. Home literacy. Socioeconomic background and literacy.

Psicol. Argum. 2014 jul./set., 32(78), 109-115 


\section{Introdução}

O conceito de home literacy pode ser definido como as práticas de leitura a que os indivíduos são expostos no contexto familiar. No Brasil, tradicionalmente, associamos essas práticas às práticas de letramento. No presente artigo pretendemos fazer uma distinção entre esses dois constructos. Argumentaremos que home literacy transcende as práticas de letramento e envolve práticas de alfabetização também.

A importância de se estudar home literacy está nas consequências que essas experiências com a língua escrita, fora do âmbito escolar, podem ter para garantir o sucesso na escolarização do próprio indivíduo ou na escolarização daqueles que convivem com eles. Por exemplo, Timons (2008) aponta que o envolvimento das famílias tem um efeito positivo sobre o processo de escolarização e que esse se sobrepõe ao impacto da escola e da comunidade.

Crianças com dificuldades de leitura geralmente vêm de famílias com baixos níveis de atividades de leitura e escrita. Além disso, há uma alta correlação entre nível socioeconômico e atraso escolar. Crianças de baixo nível socioeconômico apresentam, em geral, maiores índices de fracasso e evasão escolar, e acredita-se que nessas famílias há menos atividades de leitura e escrita.

Dificuldades na leitura e baixo nível socioeconômico são fatores que têm sido apontados sistematicamente na literatura especializada como afetando o desempenho das crianças. No entanto, quando os estudos na área pensam nos fatores ambientais que afetam o desenvolvimento da leitura e escrita, se concentram em definir o nível socioeconômico das crianças como o fator principal. O nível socioeconômico é tratado como uma variável interveniente que influencia o desenvolvimento da leitura e, por sua vez, o fracasso escolar. Uma lista de possíveis diferenças entre o ambiente das crianças de classe média e de baixa renda é apresentada, mas poucos dados empíricos são de fato apresentados para explicar quais elementos do ambiente afetam o desenvolvimento e como eles interagem com a aquisição da língua escrita.

Em uma revisão da literatura nacional na área, não achamos qualquer artigo científico que apresentasse dados empíricos sobre as práticas de letramento e alfabetização realizadas fora da escola. Defendemos que não é suficiente dizer que as crianças de nível socioeconômico baixo têm pouco acesso a livros e atividades que estimulam a escrita, precisamos demonstrar se de fato essas atividades influenciam o desempenho escolar e qual a proporção da variabilidade no desempenho da leitura que podemos atribuir a esses fatores.

Burgess, Hecht e Loningan (2002) ressaltam que o nível socioeconômico reflete vários aspectos, como atitudes, oportunidades e uma variedade de atividades que as crianças realizam. Tratado sinteticamente é pouco útil para explicar diferenças no desempenho na alfabetização. Os autores ressaltam que fatores como a leitura compartilhada de livros entre pais e as crianças são melhores preditores de sucesso na alfabetização do que uma mera medida de nível socioeconômico. Se a criança de baixa renda tem acesso a livros e é estimulada a aprender a ler, pode não se encontrar diferenças entre elas e as crianças de classe média quanto ao desempenho na leitura. Assim, a variável que devemos investigar não é o nível socioeconômico, mas as experiências a que as crianças estão expostas. Para ter um quadro claro dos fatores ambientais facilitadores da alfabetização, é preciso definir e conhecer os tipos de atividade de letramento e alfabetização a que criança tem acesso desde o início de sua vida e seu efeito do desenvolvimento linguístico. No entanto, precisamos ter uma boa definição operacional de home literacy para que isso possa ser feito de forma adequada.

Quando falamos desse constructo, do que estamos falando? A definição de home literacy como de outros constructos psicológicos não é sem controvérsia. Uma definição clara dessa habilidade é importante, porque precisamos dela para construir instrumentos de avaliação que ofereçam dados relevantes sobre o tema.

\section{O que é home literacy?}

Em um primeiro momento definiu-se home literacy como as experiências com a leitura e escrita que as crianças têm no contexto familiar. Porém, para que possamos investigar o impacto dessas experiências no processo de aquisição da língua escrita precisamos definir sua natureza. Em um estudo longitudinal, Philips e Burgess (2009) pretenderam mostrar que diferentes conceituações de home literacy geram diferentes resultados sobre o impacto 
dessa habilidade na alfabetização. Os autores investigaram seis conceituações diferentes desse constructo, avaliando crianças de quatro e cinco anos de idade. Os resultados mostraram contribuições estatisticamente significativas e positivas entre as várias medidas de home literacy e a linguagem oral, sensibilidade aos sons da fala e habilidade de leitura de palavras. No entanto, a magnitude das relações apareceu como uma função da maneira como home literacy foi conceituada. Assim, ter uma clareza do conceito empregado é fundamental para a promoção da alfabetização através do desenvolvimento de atividades que envolvam esse constructo.

As formas de se estudar as experiências de leitura na família foram sendo modificadas ao longo das duas últimas décadas. Inicialmente, as práticas de leitura na família eram estudadas sob a ótica da exposição ao material impresso, especificamente à leitura de livros compartilhada por pais e filhos, isso porque estudos empíricos demonstraram que a exposição ao material impresso é bastante importante para o desenvolvimento inicial da alfabetização.

Neuman (1999) argumenta que ao ter contato com a leitura a criança aprende que a escrita tem suas convenções e ritmos próprios, aprendendo as ferramentas conceituais associadas à leitura. Além disso, a exposição à leitura de livros pode ajudar no desenvolvimento de outras habilidades linguísticas. 0 autor desenvolveu um estudo de intervenção de exposição a livros que apresentou efeitos positivos no processo de escolarização das crianças atendidas. Além desse, outros estudos empíricos também dão ênfase a essa argumentação. 0 estudo de Apel (2010) é um dos que demonstrou que crianças em educação infantil são capazes de aprendizagem de novas palavras da língua através da exposição a livros de estória.

Apesar da importância da exposição aos livros, as pesquisas investigando essa temática têm demonstrado que há mais aspectos a serem considerados quando se trata das experiências com a leitura e escrita do que a leitura compartilhada de livros (Phillips \& Logan, 2009). Entender a natureza dessas outras atividades a que as crianças estão expostas é de grande importância, pois elas podem ter impactos diversos no desenvolvimento da alfabetização.

Em um estudo que verificou essa questão, Sénéchal, LeFevre, Thomas e Daley (1998) investigaram dois aspectos da experiência com língua escrita em casa: a leitura compartilhada de livros e o ensino da escrita feito pelos pais. As crianças no estudo tinham de quatro a cinco anos e pertenciam a famílias de classe média no Canadá. As autoras observaram que os escores das crianças nas tarefas de linguagem oral eram afetados pelas experiências de leitura compartilhada com os pais e os escores nas tarefas de escrita, pelo ensino da língua escrita. Assim, esses dois tipos de experiência na família afetam o desempenho das crianças de forma diferente. Cabe ressaltar que, ao final de um ano de estudo, as autoras mostraram que as medidas de linguagem oral contribuíram para leitura. Assim, a contribuição da leitura compartilhada de livros para alfabetização parece ser indireta, ocorrendo por meio do desenvolvimento da linguagem oral, ao passo que o ensino da escrita contribui diretamente para leitura.

Evans, Shaw e Bell (2000) estudaram a relação entre o ambiente familiar, a linguagem e o desenvolvimento da alfabetização. Os autores argumentavam que a leitura compartilhada de livros não tem um papel tão importante na aquisição da língua escrita. Para verificar sua hipótese, mediram vários aspectos do desenvolvimento da linguagem e do ambiente das crianças. Os resultados desse estudo mostraram que, depois de se controlar variáveis como a idade das crianças, a educação dos pais, os escores das crianças em tarefas como nomeação seriada rápida e medidas cognitivas, a leitura compartilhada de livros não contribuiu para as habilidades de alfabetização como nomear letras e sons no jardim de infância. Por outro lado, atividades feitas em casa que envolviam letras contribuíam de forma significativa para a variância desses escores. Para os escores de vocabulário receptivo e sensibilidade aos sons das letras, a leitura compartilhada com os pais e o conhecimento das letras não contribuíram para as habilidades de alfabetização de forma significativa. Os resultados desses autores sugerem que as experiências que têm impacto na alfabetização e desenvolvimento da linguagem são de natureza mais formal.

Sénéchal e LeFevre (2002) sugerem que se divida as atividades de leitura feitas em casa em dois grupos: atividades formais e informais. As atividades formais envolvem o ensino por parte dos pais das letras do alfabeto, escrita do nome, leitura e escrita de palavras, e as atividades informais envolvem o desenvolvimento da leitura e escrita de forma

Psicol. Argum. 2014 jul./set., 32(78), 109-115 
indireta como leitura compartilhada de livros. As primeiras estão mais associadas às práticas de alfabetização e as últimas às de letramento.

Essa divisão se assemelha com a que se faz no Brasil quando se fala de alfabetização e letramento. Alfabetização e letramento apresentavam-se como conceitos antagônicos. Letramento pode ser definido como os usos e funções da língua escrita, enquanto alfabetização é a aquisição do código escrito (Tfouni, 1995). O debate ocorria porque defensores do ensino da leitura como prática de letramento acreditavam que a aquisição do código não é suficiente para que se possa usar a escrita de forma plena. Ser alfabetizado não garante que se seja letrado. Por outro lado, defensores do ensino do código argumentam que sem esse último a criança não avança em seu processo de escolarização e não pode se tornar verdadeiramente letrada. A escrita é um código arbitrário, e ajudar a criança entendê-lo facilita o processo de sua aquisição. 0 verdadeiro letramento depende do domínio formal da escrita. Cada vez mais se entende que esses dois aspectos da aquisição da língua escrita devem caminhar juntos. Os estudos sobre home literacy demonstram que esses dois constructos não podem ser vistos como separados e que interagem no desenvolvimento da alfabetização e consequentemente da escolarização como um todo. No entanto, como sugerem Sénéchal e LeFevre (2002), é possível que estes tenham impactos diferentes sobre o desempenho escolar das crianças, mas que ainda assim se complementem.

O estudo de Sénéchal e LeFevre (2002) apresenta dados do acompanhamento de crianças ao longo de cinco anos de investigação que procurou verificar se esse é mesmo o caso (os dados iniciais foram publicados em Sénéchal et al., 1998). As autoras estavam interessadas em como diferentes atividades ligadas à linguagem oral e escrita contribuem para o desenvolvimento da leitura. As crianças dessa pesquisa foram acompanhadas e várias medidas ligadas à linguagem oral e escrita, assim como as experiências da criança com a língua escrita em casa, foram tomadas.

Os resultados mostraram que a exposição aos livros se relacionou ao desenvolvimento da linguagem oral, que contribuiu para leitura no último ano do estudo, já as habilidades de ensino da língua escrita contribuíram para a leitura diretamente.

Os resultados sugerem que as diferentes experiências com a língua escrita desenvolvem diferentes habilidades que facilitam a aquisição da leitura. Mostram também que os impactos das experiências com a língua escrita em casa não se limitam aos primórdios da alfabetização, mas continuam influenciando a leitura em anos subsequentes da escolarização.

Phillips e Loningan (2009) ressaltam que quando home literacy é definida de forma restrita, ou seja, como exposição à imprensa, o impacto dessa habilidade é mostrado apenas no desenvolvimento da linguagem oral. Porém, quando esse constructo é definido de forma mais abrangente, o impacto é sentido em habilidades emergentes da alfabetização, como a consciência fonológica e conhecimentos gerais sobre a imprensa. Os autores propõem uma ampliação da definição do conceito de home literacy, incluindo aspectos como usos e funções da língua escrita, encorajamento e valores paternos em relação à leitura, o ensino de habilidades de leitura e escrita por parte dos pais, como o ensino do nome das letras e escrita do nome, a utilização de termos que se referem à alfabetização, a modelagem dos pais em relação às práticas de leitura, o nível de educação dos pais, as atitudes dos pais em relação à educação e o próprio interesse da criança. A grande questão levantada aqui é uma mudança no foco dos estudos sobre as práticas de leitura na família de uma visão menos cognitiva para uma mais sociocultural (McGee \& Purcell-Gates, 1997).

Vemos assim que o conceito de home literacy é amplo e envolve vários aspectos que vão das práticas de letramento às práticas de alfabetização. Essas experiências influenciam o desenvolvimento da alfabetização das crianças e podem explicar parte dos fatores que afetam o fracasso escolar.

\section{Diferenças culturais e sociais}

Tentando identificar os fatores ambientais que afetam o desempenho escolar, Britto (2001) realizou um estudo longitudinal com crianças afro-americanas com baixa renda familiar. Home literacy nessas famílias foi estudada investigando três dimensões diferentes do ambiente familiar das crianças:

1. Ambiente familiar de linguagem e interações verbais: definida como tipo de linguagem a que criança está exposta em casa, incluindo usos descontextualizados da linguagem, rimar e criar 
músicas, conversar, escutar estórias e narrar experiências reais ou fictícias;

2. Clima de aprendizagem: do ponto de vista estrutural, esse aspecto foi estudado sob a ótica da presença, disponibilidade e acesso ao material impresso no lar. Do ponto de vista funcional, o clima de aprendizagem foi estudado pela mediação parental na modelagem, ensino e estilo de leitura;

3. Clima social e emocional: incluía aspectos do ambiente familiar como suporte social, interação social entre pais e filhos, jogos infantis, apoio emocional e motivação obtida no contexto familiar.

Os principais métodos de coleta de dados foram entrevistas estruturadas, medidas das habilidades selecionadas e observações naturalísticas das interações das mães com as crianças. As observações começaram quando as crianças tinham sete meses de idade e terminaram aos sete anos.

Os resultados mostraram que a dimensão da aprendizagem do ambiente familiar estava associada à interação verbal e da linguagem e à dimensão social e emocional. Depois, mostraram que nos anos da pré-escola, as habilidades de literacia das crianças estavam mais fortemente associadas aos aspectos das experiências com a linguagem na família do que às habilidades desenvolvidas pela escola, principalmente no que diz respeito ao vocabulário expressivo que estava associado às interações de linguagem e verbais e ao clima social e emocional. Além disso, a prontidão para a escolarização estava associada ao clima de aprendizagem e ao clima social e emocional.

É interessante notar que, nesse estudo, o nível de escolarização das mães aparece como uma variável independente que contribui para as habilidades de leitura das crianças tanto na educação infantil como no ensino fundamental. A escolarização das mães, dessa forma, promove um ciclo virtuoso ao longo do tempo, melhorando a educação das gerações seguintes.

Por fim, os resultados mostraram que a qualidade das interações com os pais é importante para desenvolver a aquisição da língua escrita. As crianças na educação infantil que tinham mães com estilo de leitura e ensino que refletiam as três dimensões estudadas apresentavam melhores níveis de prontidão para escolarização e melhor vocabulário expressivo.
A autora conclui, a partir desse estudo, que o ambiente familiar ao qual a criança está exposta ao nascer influenciará o aprendizado dela por um longo tempo. As experiências da criança na família que contribuem para a alfabetização e escolarização são complexas e devem ser vistas sobre várias dimensões.

0 estudo de Britto (2001) foi realizado com crianças afro-americanas, que apesar das diferenças socioculturais, residiam em um país desenvolvido com vários programas de incentivo à leitura. Menos se sabe sobre as experiências com a leitura que as crianças têm em países em desenvolvimento. Em um estudo específico sobre home literacy na América Latina, Strasser e Lissi (2009) ressaltam as diferenças culturais entre países. As autoras lembram que em países em desenvolvimento há uma grande parte da população vivendo abaixo da linha de pobreza e o estresse causado pelas condições econômicas afeta a qualidade das interações parentais em vários níveis. Além disso, o acesso a livros é difícil, uma vez que não é um item prioritário para sobrevivência.

No estudo Strasser e Lissi (2009), 126 crianças chilenas e seus pais foram entrevistados. Os resultados mostraram que apenas $54 \%$ dos pais entrevistados declararam ter lido para seus filhos na última semana. Esse resultado não surpreenderia se não fosse pelo fato de que a amostra incluía também crianças de famílias de classe média e alta. Em países desenvolvidos a taxa para essas famílias é de $50 \%$ a $60 \%$ de leitura diária. As autoras concluíram que as questões culturais ligadas às práticas de leitura transcendem as questões meramente econômicas.

Os resultados demonstraram também que as crianças chilenas matriculadas na educação infantil estão expostas a menos experiências com a escrita do que as crianças em países desenvolvidos, tanto na escola como na família. Porém, as autoras identificaram que, ainda assim, as medidas de exposição à língua escrita estavam associadas ao desempenho na alfabetização.

Esses resultados, ao mesmo tempo que apontam para necessidade de se implementar programas de acesso a livros e atividades de desenvolvimento da língua escrita, apontam para uma barreira cultural que precisa ser transposta. Cabe ressaltar que a não realização de atividades de leitura em casa não significa que esses pais não estejam interessados ou não se importem com a educação de seus filhos.

Psicol. Argum. 2014 jul./set., 32(78), 109-115 


\section{Caminhos futuros para pesquisas sobre home literacy no contexto nacional}

Levando em conta os altos índices de fracasso escolar no Brasil e o desempenho pobre dos nossos alunos na leitura, especialmente entre as camadas populares de nossa população, é surpreendente que não se encontrem estudos empíricos sobre Home literacy no Brasil. Surpreende ainda pelo fato de haver um quase consenso entre os pesquisadores da área sobre a importância desse tema.

Torna-se importante então que se inicie a busca de evidências empíricas que identifiquem os aspectos das experiências com língua escrita que influenciam o desenvolvimento da leitura. As pesquisas nessa área devem levar em conta os seguintes elementos:

1. A construção de instrumentos de avaliação baseados em uma revisão extensa da literatura, especialmente a internacional, que já avançou muito nessa área;

2. A adaptação desses instrumentos às nossas condições socioculturais;

3. A elaboração de estudos longitudinais que investiguem o impacto dessas experiências na escolarização;

4. Estudos de intervenção, baseados nos dados das pesquisas, que atuem na prevenção e remediação do fracasso escolar.

A construção de instrumentos adequados é fundamental para investigação em qualquer área de estudo. Dificuldades sempre são encontradas em investigações que necessitam de relatos pessoais sobre um determinado tema. Obter informações reais sobre um tema em que há respostas claramente aceitas socialmente pode ser um desafio a mais para o pesquisador.

Além disso, a adaptação cultural dos experimentos é muito importante. Britto (2001) ressalta que para crianças de determinadas culturas em que os livros não são muito presentes as interações da mãe com a criança que visam à expansão da linguagem são importantes preditores da alfabetização. No estudo já citado sobre crianças chilenas, Strasser e Lissi (2009) substituíram a pergunta tradicional sobre a frequência de visita a bibliotecas, dos questionários sobre home literacy, por outras mais condizentes com o contexto cultural chileno, uma vez que não há muitas bibliotecas públicas no Chile.

0 desenvolvimento de estudos longitudinais pode nos mostrar a proporção do impacto dessas experiências no desempenho da leitura e escolar de um modo geral. Esses estudos são importantes para subsidiar intervenções que por sua vez devem ter seu impacto no sucesso acadêmico medido.

Reese, Sparks e Leyva (2010) chamam atenção para o fato de que os pais são os primeiros professores das crianças, e não é a toa que os programas de desenvolvimento da alfabetização realizados, em geral nos países norte-americanos, têm mais sucesso quando envolvem a família. Esses estudos precisam ser cuidadosamente elaborados. Portanto, pensamos que as etapas de desenvolvimento de instrumentos, adaptação cultural, estudos longitudinais e intervenção são fundamentais para que se organize um programa de pesquisa nessa área que possa vir a obter informações que possam melhorar de fato o desempenho escolar de nossas crianças.

\section{Conclusões}

Ainda não há no Brasil estudos empíricos sobre os impactos da home literacy no contexto educacional brasileiro. Em geral, essa questão é discutida no âmbito das reflexões teóricas sobre a prontidão para alfabetização e sobre as práticas de letramento e de ensino da língua escrita.

Qualquer estudo de intervenção eficaz nessa área precisará identificar quais os elementos das experiências com a leitura em casa que promovem o desenvolvimento das crianças no contexto específico que ocorrem. Para isso é preciso identificar empiricamente esses elementos. Esses estudos devem envolver tanto observações naturalísticas como métodos mais objetivos de coleta de dados, de forma que os dados observados se complementem e ofereçam um quadro mais claro da realidade brasileira. Assim, abre-se um promissor campo de estudo para pesquisadores e educadores interessados na melhoria da qualidade da educação de nossas crianças. 


\section{Referências}

Apel, K. (2010). Kindergarten children's initial spoken and written word learning in a storybook context. Scientific Studies in Reading, 14(5), 440-463.

Britto, P. (2001). Family literacy environments and young children's emerging literacy skills. Reading Research Quarterly, 36(4) 346-348.

Burgess, R. S., Hecht, S. A., \& Lonigan, C. J. (2002). Relations of the home literacy environment (HLE) to the development of reading-related abilities: A one-year longitudinal study. Reading Research Quarterly, 37(4), 408-426.

Evans, M. A., Shaw, D. \& Bell, M. (2000). Home literacy activities and their influence on early literacy skills. Canadian Journal of Experimental Psychology, 54(92), 65-77.

McGee, L \& Purcell-Gates, V (1997). So What's Going on in Research on Emergent Literacy? Reading Research Quarterly, 310-318.

Neuman, S. (1999). Books make a difference: a study of access to Literacy. Reading Research Quarterly, 34(3), 286-311.
Philips, B. M. \& Burgess, C. J. (2009). Variations in the home literacy environment of preschool children: a cluster analytic approach. Society for the Scientific Study of Reading, 13(2), 146-174.

Reese, E., Sparks, A., \& Leyva, D. (2010). A review of parent interventions for preschool children's language and emergent literacy. Journal of Early Childhood Literacy, 10(1), 97-117

Sénéchal, M., LeFevre, J., Thomas, E., \& Daley, K. (1998). Reading Research Quarterly, 33(1), 96-116.

Sénéchal, M \& LeFevre, J. (2002). Parental involvement in the development of children reading skill. Child Development, 73(2), 445-460.

Strasser, K., \& Lissi, M. R. (2009). Home and instruction effects on emergent literacy in a sample of Chilean kindergarten children. Society for the Scientific Studies of Reading, 13(2), 175-204.

Tfouni, L.V. (1995). Letramento e alfabetização. São Paulo: Cortez,

Timons (2008). Challenges in researching family literacy programs. Canadian psychology, 49(2), 96-102.

Psicol. Argum. 2014 jul./set., 32(78), 109-115 